\title{
Taxation and Labor Markets
}

\author{
Pierre M. Picard* \\ Eric Toulemonde ${ }^{\dagger}$ \\ University of Manchester University of Namur
}

January 25, 2000

\begin{abstract}
We exploit the common features of models such as union-firm wage bargaining, search and efficiency wage models to develop a framework that can be used for analyzing the effects of any budget-neutral tax reform on employment in these models. We show that taxes paid by workers are not equivalent to taxes paid by firms when taxes are non linear. Moreover, increasing progressivity is good for employment in these models.
\end{abstract}

${ }^{*}$ University of Manchester, School of Economic Studies, Oxford Road, Manchester MP13 9PL. E-mail: Pierre.Picard@man.ac.uk.

${ }^{\dagger}$ Chargé de recherches at the National Fund for Scientific Research (Belgium), C.R.E.W. and G.R.E.B.E., University of Namur, Department of Economics, 8 rempart de la Vierge, 5000 Namur, Belgium. Email: eric.toulemonde@fundp.ac.be. 


\section{Introduction}

Unemployment has been a major problem in most parts of Europe for many years. High labor costs are often blamed for being responsible for this situation. Therefore, many governments are urged to reduce labor costs by restructuring their taxes and particularly by reducing them (see for example the recommendations of the European Commission's White Paper on growth, competitiveness, employment). However, such reforms are difficult to apply because they reduce the governments' revenues. To compensate for this reduction, governments must either increase other taxes, or reduce their spending, which is a difficult political task. Therefore, it is useful to examine how a restructuring of taxes that is budget-neutral could increase employment, since a restructuring would be politically easier to apply.

We analyze two types of budget-neutral tax restructuring. First we examine whether a switch of taxes from firms to workers could affect employment. Conventional wisdom says that who pays the tax is irrelevant to employment (see Blinder (1988)). The key element lies in the elasticities of the demand for labor and the labor supply. This result holds in competitive markets and, depending on the formalization, in many imperfectly competitive labor markets. However several empirical studies show that taxes on firms and workers have different effects on wages and employment, contrary to the theoretical predictions (see for example Calmfors (1990), Lockwood and Manning (1993) or Tyrväinen (1995)). To break the equivalence result, assumptions have been made on the way that unemployment benefits are affected by the tax reform (see Goerke (1999), Picard and Toulemonde (1999)). In this paper, we show that these assumptions are not necessary. Non linearities in taxes also break the equivalence result.

Second, we analyze the effect of progressivity on employment. The literature shows that progressivity is good for employment. Through higher marginal tax rates, tax progression reduces the benefits of raising wages and therefore mod- 
erates wages (see Hersoug (1984), Hoel (1990), Lockwood and Manning (1993), Koskela and Vilmunen (1996), Pissarides (1998), Andersen and Rasmussen (1999) or Sørensen (1999)). We generalize this result.

Several problems arise with the above mentioned literature. First, the models generally apply to particular models of wage determination (with some exceptions, like Pissarides (1998)). Since we do not know which model of wage determination is the most suitable in Europe, it would be better to derive conclusions that do not depend on the model under study. Hence, there is a need of a unifying framework that would exploit the common features of non competitive labor markets models, hoping that these common features would be sufficient to draw general conclusions. Second in order to be tractable, many models need specific functional forms for the labor demand, the union utility, ... Drawing conclusions on more general functions would be desirable. Finally, tractability sometimes restricts the model to a simple linear taxation scheme. However, as emphasized by Lockwood and Manning (1993), actual taxation schemes are highly non linear. The assumption of non linear taxation affects some results, particularly when the emphasis is put on the equivalence of taxes paid by workers and firms.

In response to these problems, we develop a generic model that exploits the common features of union-firm wage bargaining, search and efficiency wage models. Other models fulfilling a fairly general condition are also included in our analysis. None of the conclusions that we draw depend on which specific wage determination model we choose. We also use general functions and, for the most part of the paper, a non linear taxation scheme. Results indicate that taxing workers is not equivalent to taxing firms only when the taxation scheme is non linear. Moreover, increasing progressivity is good for employment in this generic model since it reduces the incentives to increase wages.

Section 2 presents the framework of the model and analyzes in a very general way how taxation influences employment. Section 3 develops the generic wage determination process that encompasses union-firm wage bargaining, search and 
efficiency wage models. The issue of tax equivalence and progressivity are studied. This is followed by concluding remarks.

\section{The Framework}

In any labor market there is a market wage $w$ determined by the agents (firms and/or workers). It is used as the taxation base for the computation of the net wage $(\underline{w})$ and the gross wage $(\bar{w})$. For example the net wage could be a linear function of the market wage: $\underline{w}=\alpha_{0}+\alpha_{1} w$ where $\alpha_{0}$ and $\alpha_{1}$ are constant taxation parameters. The tax paid by workers is $T \equiv w-\underline{w}=-\alpha_{0}+\left(1-\alpha_{1}\right) w$. Therefore $\left(1-\alpha_{1}\right)$ is the taxation rate and $\alpha_{0}$ is a lump sum paid to the workers ${ }^{1}$. However, actual tax systems are usually not linear. Non linearities will affect the analysis. Therefore, we propose a more general tax structure in which the net and gross wages are related to the market wage by the following functions $\underline{W}(w, \alpha)$ and $\bar{W}(w, \beta)$ :

$$
\underline{w}=\underline{W}(w, \alpha) \text { and } \bar{w}=\bar{W}(w, \beta),
$$

where $\alpha=\left(\alpha_{0}, \ldots, \alpha_{i}, \ldots, \alpha_{n-1}\right)$ and $\beta=\left(\beta_{0}, \ldots, \beta_{j}, \ldots, \beta_{m-1}\right)$ are the vectors of taxation parameters. Vector $\alpha$ transforms the market wage into the net wage while vector $\beta$ relates the market wage to the gross wage. We assume that $\underline{W}(w, \alpha)$ and $\bar{W}(w, \beta)$ are continuously differentiable. For example $\underline{w}=\underline{W}(w, \alpha)$ could be the following polynomial $\underline{w}=\alpha_{0}+\alpha_{1} w+\alpha_{2} w^{2}+\alpha_{3} w^{3}+\ldots$

We assume that the labor supply increases only with the net wage: $L^{S}=$ $L^{S}(\underline{w})$. It could also be affected by the unemployment benefit, but throughout the paper we assume that this benefit is constant ${ }^{2}$. The firm's demand for labor is usually decreasing in the gross wage $\bar{w}$. However, it could also be increasing in the

\footnotetext{
${ }^{1}$ Note that $T$ can equivalently be written in terms of a tax rate $\left(1-\alpha_{1}\right)$ and an exemption $\alpha_{0} /\left(1-\alpha_{1}\right): T=\left(1-\alpha_{1}\right)\left(w-\alpha_{0} /\left(1-\alpha_{1}\right)\right)$.

${ }^{2}$ See Goerke (1999) or Picard and Toulemonde (1999) for the role of unemployment benefits in similar models.
} 
net wage $\underline{w}$. For example, in efficiency wage models, the effort of workers could be increasing in the net wage. Therefore, workers' productivity also increases with $\underline{w}$. Thus the demand for labor increases with the net wage. Written generally, we have each firm's labor demand is $N^{D}(\underline{w}, \bar{w})$. When there are $n$ identical firms, the aggregate labor demand becomes $N^{A}=n N^{D}(\underline{w}, \bar{w})$.

Changes in $\alpha$ and $\beta$ modify the market wage. At this stage we adopt a general formulation for the wage determination. It is expressed as follows:

$$
F(w, \alpha, \beta)=0
$$

The government's budget vary with the market wage and the taxation parameters $\alpha$ and $\beta$ in the following way:

$$
G \equiv(\bar{w}-\underline{w}) n N^{D}(\underline{w}, \bar{w})-b\left(L^{S}(\underline{w})-n N^{D}(\underline{w}, \bar{w})\right)-G^{0}=0
$$

where $G^{0}$ is the value of a public good and $b$ is the unemployment benefit ${ }^{3}$ which is assumed to be constant. The first term represents taxes levied on workers. The second term is the cost of the unemployment benefit and the last term is the cost of a public good. This expression can be written as

$$
G(w, \alpha, \beta)=0
$$

Note that in contrast to expression (1) the taxation parameters $\alpha$ and $\beta$ enter the budget only through net and gross wages. Hence, (2) can be reduced to

$$
\Psi(\underline{w}, \bar{w})=0
$$

We assume that $F(w, \alpha, \beta)$ and $G(w, \alpha, \beta)$ are continuously differentiable. To simplify the analysis, we also assume that expression (3) can be written as $\underline{w}=\psi(\bar{w})$. Therefore, $L=N^{D}(\underline{w}, \bar{w})=N^{D}(\psi(\bar{w}), \bar{w}) \equiv L^{D}(\bar{w})$. An increase in the gross wage might have two opposite effects on the demand for labor. On the

\footnotetext{
${ }^{3}$ Note that the remaining of the analysis holds for any $b$ that depends on net and gross wages only.
} 
one hand, it increases firms' costs and therefore decreases their demand for labor.

On the other hand, it increases the net wage (via expression (3)) and therefore increases the workers' effort and the demand for labor. We assume that the first effect dominates the second, that is, we suppose that $L^{D \prime}<0$.

To sum up, the framework of the model consists of five equations. The two first relate the net and gross wages to the market wage: $\underline{w}=\underline{W}(w, \alpha)$ and $\bar{w}=\bar{W}(w, \beta)$. The third is the demand for labor: $L=L^{D}(\bar{w})$ which is decreasing in the gross wage. The fourth is the wage equation (1) and the fifth is the government's budget (3) which can equivalently be written as (2).

In the remainder of this section we check how the government can adjust parameters $\alpha$ and $\beta$ to increase the employment level while keeping the budget constant. Any change in the gross wage modifies the employment level:

$$
d L=L^{D^{\prime}} d \bar{w}=L^{D^{\prime}}\left(\bar{W}_{w} d w+\sum_{j} \bar{W}_{\beta_{j}} d \beta_{j}\right) .
$$

Parameters $\beta$ directly affect the demand for labor by changing the gross wage, given the market wage $w$. This effect is represented by the second term in the brackets of the above equation. Parameters $\alpha$ and $\beta$ affect indirectly the demand for labor by altering the market wage $w$. This is represented by the first term in the brackets of the above equation.

We assume that there exists at least one taxation parameter $\alpha_{0}$ (or $\beta_{0}$ ) under the government's control that has an impact on the wage and the budget: $F_{\alpha_{0}}, G_{\alpha_{0}} \neq 0$. The tax parameter $\alpha_{0}$ and the market wage $w$ can always be endogenously set to fulfill equations (1) and (2). As shown in Appendix 1, any change in parameters $\alpha_{i \neq 0}$ or $\beta_{j}$ can be compensated by endogenous changes in $\alpha_{0}$ and $w$ in order to satisfy these equations. Totally differentiating (1) and (2) 
and substituting the values of $d \alpha_{0}$ and $d w$ in (4) gives

$$
\begin{aligned}
d L & =\left(\sum_{i \neq 0} A_{i} d \alpha_{i}+\sum_{j} B_{j} d \beta_{j}\right) \text { with } \\
A_{i} & =-L^{D^{\prime}} \frac{\bar{W}_{w}}{\frac{G_{w}}{G_{\alpha_{0}}}-\frac{F_{w}}{F_{\alpha_{0}}}}\left[\frac{G_{\alpha_{i}}}{G_{\alpha_{0}}}-\frac{F_{\alpha_{i}}}{F_{\alpha_{0}}}\right] \forall i \neq 0 \text { and } \\
B_{j} & =-L^{D^{\prime}} \frac{\bar{W}_{w}}{\frac{G_{w}}{G_{\alpha_{0}}}-\frac{F_{w}}{F_{\alpha_{0}}}}\left[\left(\frac{G_{\beta_{j}}}{G_{\alpha_{0}}}-\frac{\bar{W}_{\beta_{j}}}{\bar{W}_{w}} \frac{G_{w}}{G_{\alpha_{0}}}\right)-\left(\frac{F_{\beta_{j}}}{F_{\alpha_{0}}}-\frac{\bar{W}_{\beta_{j}}}{\bar{W}_{w}} \frac{F_{w}}{F_{\alpha_{0}}}\right)\right] \forall j .
\end{aligned}
$$

With these expressions, we are able to compute the full effects of a budget-neutral reform of taxes on employment. We have the following proposition:

Proposition A budget-neutral restructuring of taxes has no impact on employment if and only if $\forall i \neq 0$ and $\forall j, A_{i}=B_{j}=0$. If there exists a tax parameter $\alpha_{i \neq 0}$ or $\beta_{j}$ such that $A_{i} \neq 0$ or $B_{j} \neq 0$, then it is possible to increase employment and to keep the budget constant by an appropriate change in this parameter and in $\alpha_{0}$.

Picard and Toulemonde (1999) show that the restructuring of linear taxes is irrelevant to employment if the wage setting process and the budget are functions of only net and gross wages. It is now easy to extend their result to non linear taxation scheme:

Corollary 1 Suppose that the wage setting process and the budget are functions of only net and gross wages $F(w, \alpha, \beta)=\Phi(\underline{w}, \bar{w})$ and $G(w, \alpha, \beta)=\Psi(\underline{w}, \bar{w})$. Then the taxation scheme is irrelevant to employment $\left(A_{i \neq 0}=B_{j}=0\right)$.

Proof. We have $F_{\alpha_{i}}=\Phi_{1} \underline{W}_{\alpha_{i}}, F_{\beta_{j}}=\Phi_{2} \bar{W}_{\beta_{j}}, F_{w}=\Phi_{1} \underline{W}_{w}+\Phi_{2} \bar{W}_{w}, G_{\alpha_{i}}=$ $\Psi_{1} \underline{W}_{\alpha_{i}}, G_{\beta_{j}}=\Psi_{2} \bar{W}_{\beta_{j}}$ and $G_{w}=\Psi_{1} \underline{W}_{w}+\Psi_{2} \bar{W}_{w}$. Substituting in (6) and (7) and simplifying yield the result.

On the one hand, this corollary implies that if $F(w, \alpha, \beta)=\Phi(\underline{w}, \bar{w})$, there is no gain from altering the progressivity of the tax scheme or from increasing its complexity. Also, there is no gain from swapping taxation from the firm 
to the workers. On the other hand, if the conditions of the corollary are not satisfied, employment improvements can be obtained by rising (decreasing) the tax parameters for which $A_{i \neq 0} \neq 0$ or $B_{j} \neq 0$. We present here two interesting cases.

Competitive labor markets When the labor market clears, we have

$$
F \equiv n L^{D}(\bar{w})-L^{S}(\underline{w})=0 .
$$

Since the wage setting process and the budget depend only on the net and the gross wages, Corollary 1 applies and yields the Dalton's (1954) result on the irrelevance of tax incidence: in a competitive labor market, a budget-neutral restructuring of taxes is irrelevant to employment.

Minimum wages The irrelevance of tax incidence may also hold in case of minimum wages. If it is the net wage (or the gross wage) that is constrained by the minimum value $\widetilde{w}^{\min }$, then $\underline{w}=\widetilde{w}^{\min }$ (or, $\bar{w}=\widetilde{w}^{\min }$ ). Both $F$ and $G$ are functions of net and gross wages only. Therefore, according to Corollary 1, any revenue neutral restructuring of taxes is irrelevant to employment.

At this stage we are not able to draw many conclusions about the equivalence (or non equivalence) of taxes paid by workers and employers. Neither are we able to predict the effect of tax progressivity on employment. To draw such conclusions, we must slightly restrict the wage determination process.

\section{Generic Model for Imperfect Labor Markets}

In this section we provide a model that encompasses some of the most discussed models of imperfect labor markets. By abuse of language, we call this model 'generic' because it will generate results for a large class of models, which include the union bargaining, the search and the efficiency wage models. We show that 
taxing firms might not be equivalent to taxing workers and that marginal taxes and tax progressivity must generally be increased to improve employment.

Assume that the market wage is the result of the maximization of an objective $P(\underline{w}, \bar{w}, \Gamma):$

$$
\max _{w} P(\underline{w}, \bar{w}, \Gamma)
$$

where the term $\Gamma$ is the alternative revenue of workers. $\Gamma$ may depend on the net wage received in other firms $\underline{\omega}$, the net unemployment benefit $b$ and the probability of being employed or unemployed ${ }^{4}$. The probability $p$ of being employed depends on the labor supply and the labor demand which are themselves related to the net and gross wages in the economy, thus $p=p(\underline{\omega}, \bar{\omega})$. In short,

$$
\Gamma=\Gamma(\underline{\omega}, \bar{\omega}) .
$$

Assuming an interior solution, this gives the following wage setting expression:

$$
F(w, \alpha, \beta) \equiv \underline{W}_{w} P_{1}(\underline{w}, \bar{w}, \Gamma)+\bar{W}_{w} P_{2}(\underline{w}, \bar{w}, \Gamma)=0
$$

In a symmetric equilibrium, $\underline{w}=\underline{\omega}$ and $\bar{w}=\bar{\omega}$. Thus $\Gamma=\Gamma(\underline{w}, \bar{w})$. For readability, we write $P_{1}$ and $P_{2}$ as $Q(\underline{w}, \bar{w})$ and $R(\underline{w}, \bar{w})$ respectively. Equation (9) becomes

$$
F=\underline{W}_{w} Q(\underline{w}, \bar{w})+\bar{W}_{w} R(\underline{w}, \bar{w})=0 .
$$

We assume that $Q(\underline{w}, \bar{w})$ and $R(\underline{w}, \bar{w})$ take values that are different from zero. As we will see, in most models, the objective $P$ rises with the net wage because the net wage increases the utility of workers, which is valued positively by the agents. We also expect that the objective $P$ decreases with the gross wage, because this is a cost paid by firms. Therefore, we expect that $Q$ is positive and $R$ negative. We assume that the second order condition $F_{w}<0$ is satisfied.

\footnotetext{
${ }^{4}$ See Layard et al. (1991) for a similar definition of the alternative revenue in efficiency wage models and in union models.
} 
To sum up, the generic model consists of a wage determination process that has the following three properties: it is the result of the maximization of an objective $P(\underline{w}, \bar{w}, \Gamma)$ and an outside option $\Gamma(\underline{\omega}, \bar{\omega})$ that are affected by taxation only through net and gross wages; it is consistent with symmetric equilibrium $\underline{w}=\underline{\omega}$ and $\bar{w}=\bar{\omega}$; finally, it is expressed as (10) with $Q(\underline{w}, \bar{w})>0$. The last property will become clearer in the following paragraphs.

To sum up, we may define the following three properties of our generic model.

Definition: The generic model consists of a wage determination process

(1) that results from the maximization of an objective $P(\underline{w}, \bar{w}, \Gamma)$ where $\Gamma(\underline{\omega}, \bar{\omega})$ is an outside option;

(2) that is consistent with symmetric equilibrium $\underline{w}=\underline{\omega}$ and $\bar{w}=\bar{\omega}$;

(3) that is expressed as (10) with $Q(\underline{w}, \bar{w})>0$.

The role of the third property will become clearer in the following paragraphs. Many models in the literature of taxation under imperfect labor markets fit this generic model. So are the union bargaining, the search and the efficiency wage models.

Union Bargaining Model The union utility is $U(L, \underline{w}, \Gamma)$ where $\Gamma$ is the outside option defined in (8) and where $U_{1}, U_{2}>0$. It is usually assumed that the firm's profits are $\Pi(L, \bar{w})$ yielding a labor demand $L^{D}(\bar{w})$. The wage bargaining with the firm's right to manage is equivalent to the maximization of the Nash product:

$$
\max _{w} P \Leftrightarrow \max _{w} U^{\beta} * \Pi^{1-\beta}
$$

where $\beta$ is the union bargaining power and the fall-back levels have been set to zero $^{5}$. The objective $P$ is the Nash product $U^{\beta} * \Pi^{1-\beta}$ which depends only on

\footnotetext{
${ }^{5}$ This simplifying assumption is generally made in this kind of literature (see Booth (1995) for example).
} 
$(\underline{w}, \bar{w}, \Gamma)$. One also has $d \Pi / d w=-\bar{W}_{w} L^{D}$. This yields the first order condition

$$
F \equiv \underline{W}_{w} \beta U_{2} \Pi-\bar{W}_{w}\left[(1-\beta) L^{D} U-\beta U_{1} L^{D^{\prime}} \Pi\right]=0
$$

which has the same structure as (10). In this example, $Q(\underline{w}, \bar{w})=\beta U_{2} \Pi>0$. Note that union monopoly models are encompassed in bargaining models for $\beta=1$.

Search Model For this example, we largely build on search models developed by Pissarides $(1990,1998)$. The point of departure of these models is that it takes time for firms and workers to find a suitable partner. Keeping a job vacant during that time is costly for the firm. Being unemployed and searching for a new job represents an opportunity cost for the worker. Hence, each existing match is associated to a rent that each employed worker $i$ shares with her employer. Worker $i$ 's gain from reaching an agreement with her employer is $E_{i}-U$, where $E_{i}$ is $i$ 's return from continuous employment and $U$ is the return to each unemployed worker. The firm's gain from an agreement is $J_{i}-V$, where $J_{i}$ is the firm's return from employing worker $i$ and $V$ is the return from keeping the job vacant. Typically, $E_{i}$ positively depends on the net wage received by worker $i$, and $J_{i}$ depends negatively on the gross wage paid by the firm. $U$ and $V$ can be related to $\Gamma{ }^{6}$ Finally, the wage is determined as the solution of the following Nash bargaining between the worker and the firm:

$$
\max _{w} P \Leftrightarrow \max _{w}\left(E_{i}(\underline{w})-U(\Gamma)\right)^{\beta} *\left(J_{i}(\bar{w})-V(\Gamma)\right)^{1-\beta} .
$$

The objective $P$ is the Nash product $\left(E_{i}-U\right)^{\beta} *\left(J_{i}-V\right)^{1-\beta}$ which depends only on $(\underline{w}, \bar{w}, \Gamma)$. Maximizing $P$ with respect to $w$ is equivalent to maximizing $\beta \ln \left(E_{i}(\underline{w})-U(\Gamma)\right)+(1-\beta) \ln \left(J_{i}(\bar{w})-V(\Gamma)\right)$ with respect to the same variable. This yields

$$
F \equiv \underline{W}_{w} \frac{\beta E_{i}^{\prime}}{E_{i}(\underline{w})-U(\Gamma)}+\bar{W}_{w} \frac{(1-\beta) J_{i}^{\prime}}{J_{i}(\bar{w})-V(\Gamma)}=0
$$

\footnotetext{
${ }^{6}$ See Pissarides $(1990,1998)$ for the exact definitions of $E_{i}, U, J_{i}$ and $V$.
} 
which has the same structure as (10). Thus, $Q(\underline{w}, \bar{w})=\beta E_{i}^{\prime} /\left(E_{i}(\underline{w})-U(\Gamma)\right)$ $>0$.

Efficiency Wage Model Shapiro and Stiglitz (1984) propose a model based on the worker's shirking behavior in which unemployment involves a discipline effect. The larger is the unemployment rate, the lower is the worker's probability to find a new job when fired. Therefore, his incentive to shirk is lower and he increases his effort. In the spirit of Pisauro (1991) or Rasmussen (1997) we use a simplified and generalized version of the Shapiro and Stiglitz model by assuming that the worker's effort $e$ depends on the net wage $\underline{w}$ and some outside reference $\Gamma:$

$$
e=e(\underline{w}, \Gamma)
$$

In such models ${ }^{7}$, the firm's profits are $F(N . e(\underline{w}, \Gamma))-\bar{w} N$ where $N$ is the employment level. On the one hand, the wage maximizes the effort per unit of labor cost. Thus

$$
\max _{w} P \Leftrightarrow \max _{w} \frac{e(\underline{w}, \Gamma)}{\bar{w}}
$$

which yields the following modified Solow condition:

$$
F \equiv \underline{W}_{w} \bar{w} e_{1}(\underline{w}, \Gamma)-\bar{W}_{w} e(\underline{w}, \Gamma)=0 .
$$

This expression has the same structure as $(10)$. Note that, $Q(\underline{w}, \bar{w})=\bar{w} e_{1}(\underline{w}, \Gamma)>$ 0 . Let $e^{*}=e^{*}(\underline{w}, \bar{w})$ be the optimal effort obtained in (13).

On the other hand, the employment level maximizes the profit function given the optimal effort. So, $N^{D}=\left(1 / e^{*}\right) F^{\prime-1}\left(\bar{w} / e^{*}\right)$. Then, $N^{D}=N^{D}(\underline{w}, \bar{w})$. Under the simplifying assumption of section $1, N^{D}(\psi(\bar{w}), \bar{w})=L^{D}(\bar{w})$ which is decreasing.

\footnotetext{
${ }^{7}$ Note that this version of the Shapiro and Stiglitz model (1984) is equivalent to the Solow model (1979) when $e_{2}=0$. It is equivalent to the Akerlof and Yellen (1990) model when $e=f(\underline{w} / \Gamma)$ where $\Gamma=\underline{\omega}$.
} 


\subsection{Improvement in Employment}

We first check whether it is possible to move some $\alpha_{i}$ in order to increase employment (see equation (5) and (6)). In the appendix we show that in the generic model, expressions (6) and (7) can be simplified to

$$
\begin{aligned}
A_{i \neq 0} & =-\Omega \bar{W}_{w} \underline{W}_{\alpha_{i}}\left[\frac{\underline{W}_{w \alpha_{0}}}{\underline{W}_{\alpha_{0}}}-\frac{\underline{W}_{w \alpha_{i}}}{\underline{W}_{\alpha_{i}}}\right], \\
B_{j} & =-\Omega \underline{W}_{w} \bar{W}_{\beta_{j}}\left\{\left[\frac{\underline{W}_{w w}}{\underline{W}_{w}}-\frac{\bar{W}_{w w}}{\bar{W}_{w}}\right]+\left[\frac{\bar{W}_{w \beta_{j}}}{\bar{W}_{\beta_{j}}}-\frac{\underline{W}_{w \alpha_{0}}}{\underline{W}_{\alpha_{0}}}\right]\right\}, \\
\text { where } \Omega & =L^{D^{\prime}} \frac{Q(\underline{w}, \bar{w})}{\left[\frac{G_{w}}{G_{\alpha_{0}}}-\frac{F_{w}}{F_{\alpha_{0}}}\right] F_{\alpha_{0}}} .
\end{aligned}
$$

The term $\Omega$ is the impact of the labor market model on employment whereas the other terms in expressions (14) and (15) incorporate the impact of the taxation schedules. By the previous assumptions, we know that $F_{\alpha_{0}}, \underline{W}_{\alpha_{i}}, \bar{W}_{\beta_{j}}$ and $Q(\underline{w}, \bar{w})$ are different from zero. As we will show later, $G_{w} / G_{\alpha_{0}}-F_{w} / F_{\alpha_{0}} \neq 0$. Assuming that $\bar{W}_{w} \neq 0$ and $\underline{W}_{w} \neq 0$ yields the following proposition.

Proposition 2 In the generic model,

(i) a budget-neutral change in the tax parameter $\alpha_{i \neq 0}$ is irrelevant to employment if

$$
\frac{\underline{W}_{w \alpha_{0}}}{\underline{W}_{\alpha_{0}}}-\frac{\underline{W}_{w \alpha_{i}}}{\underline{W}_{\alpha_{i}}}=0
$$

(ii) a budget-neutral change in the tax parameter $\beta_{j}$ is irrelevant to employment if

$$
\left[\frac{\underline{W}_{w w}}{\underline{W}_{w}}-\frac{\bar{W}_{w w}}{\bar{W}_{w}}\right]+\left[\frac{\bar{W}_{w \beta_{j}}}{\bar{W}_{\beta_{j}}}-\frac{\underline{W}_{w \alpha_{0}}}{\underline{W}_{\alpha_{0}}}\right]=0
$$

Otherwise it is always possible to improve employment by restructuring taxes.

Proof. See Appendix 2. 


\subsection{Equivalence and Non Equivalence}

In this section, we study whether a budget-neutral shift of a tax on firms to a tax on workers has an incidence on employment. We show that non-linear tax schedules are not equivalent whereas linear taxes schedules are. The idea is to check whether a change in some firm taxation parameters $\beta_{i}$ that is compensated by a change in the corresponding worker taxation parameters $\alpha_{i}$ fulfills the conditions of Proposition 2.

Linear Tax Schedules. First assume that

$$
\begin{aligned}
& \underline{w}=\alpha_{0}+\alpha_{1} w \\
& \bar{w}=\beta_{0}+\beta_{1} w .
\end{aligned}
$$

Does a change in $\beta_{0}$ modify the employment level when it is compensated by a change in $\alpha_{0}$ ? To answer this question, it suffices to compute the value of $B_{0}$. We find that $\bar{W}_{w}=\beta_{1}, \bar{W}_{w w}=0, \underline{W}_{w}=\alpha_{1}, \underline{W}_{w w}=0, \underline{W}_{\alpha_{0}}=1, \underline{W}_{w \alpha_{0}}=0$, $\bar{W}_{\beta_{0}}=1, \bar{W}_{w \beta_{0}}=0$. Therefore, $B_{0}=0$ : any change in $\beta_{0}$ that is compensated by a change in $\alpha_{0}$ has no impact on employment. Increasing the lump sum to the firm in exchange of a decrease in the lump sum of the workers has no impact on employment when the tax schedule is affine. The two taxes $\alpha_{0}$ and $\beta_{0}$ are equivalent for employment.

Secondly redefine $\alpha_{0}$ and $\beta_{0}$ as the tax coefficients of $w$ and $\alpha_{1}, \beta_{1}$ as the lump sum transfers:

$$
\begin{aligned}
& \underline{w}=\alpha_{1}+\alpha_{0} w \\
& \bar{w}=\beta_{1}+\beta_{0} w .
\end{aligned}
$$

Does a change in $\beta_{0}$ modify the employment level when it is compensated by a change in $\alpha_{0}$ ? We find that $\bar{W}_{w}=\beta_{1}, \bar{W}_{w w}=0, \underline{W}_{w}=\alpha_{1}, \underline{W}_{w w}=0, \underline{W}_{\alpha_{0}}=w$, $\underline{W}_{w \alpha_{0}}=1, \bar{W}_{\beta_{0}}=w, \bar{W}_{w \beta_{0}}=1$. Hence, $B_{0}=0$ : any change in $\beta_{0}$ that is compensated by a change in $\alpha_{0}$ has no impact on employment. Increasing the 
marginal taxation of the firm in exchange of a decrease in the marginal taxation of the workers has no impact on employment when the tax schedule is affine. This is the result presented in Pisauro (1991) or Picard and Toulemonde (1999).

Non Linear Tax Schedules. We now do the same exercise with quadratic functions. First

$$
\begin{aligned}
& \underline{w}=\alpha_{0}+\alpha_{1} w+\alpha_{2} w^{2} \\
& \bar{w}=\beta_{0}+\beta_{1} w+\beta_{2} w^{2} .
\end{aligned}
$$

It is straightforward to show that $\bar{W}_{w}=\beta_{1}+2 \beta_{2} w, \bar{W}_{w w}=2 \beta_{2}, \underline{W}_{w}=\alpha_{1}+2 \alpha_{2} w$, $\underline{W}_{w w}=2 \alpha_{2}, \underline{W}_{\alpha_{0}}=1, \underline{W}_{w \alpha_{0}}=0, \bar{W}_{\beta_{0}}=1, \bar{W}_{w \beta_{0}}=0$. Therefore, $B_{0}$ is different from zero. In contrast to the affine example, any change in $\beta_{0}$ that is compensated by a change in $\alpha_{0}$ has an impact on employment. Increasing the lump sum to the firm in exchange for a decrease on the lump sum of the workers changes employment when the tax schedule is quadratic. The two tax parameters $\alpha_{0}$ and $\beta_{0}$ are not equivalent for employment.

Finally, let us use now

$$
\begin{aligned}
& \underline{w}=\alpha_{1}+\alpha_{0} w+\alpha_{2} w^{2}, \\
& \bar{w}=\beta_{1}+\beta_{0} w+\beta_{2} w^{2} .
\end{aligned}
$$

This implies $\bar{W}_{w}=\beta_{1}+2 \beta_{2} w, \bar{W}_{w w}=2 \beta_{2}, \underline{W}_{w}=\alpha_{1}+2 \alpha_{2} w, \underline{W}_{w w}=2 \alpha_{2}$, $\underline{W}_{\alpha_{0}}=w, \underline{W}_{w \alpha_{0}}=1, \bar{W}_{\beta_{0}}=w, \bar{W}_{w \beta_{0}}=1$. Hence $B_{0}$ is different from zero. Again, this contrasts with the linear case. Any change in the marginal taxation of the firm compensated by a change in the marginal taxation of workers has an impact on employment when the tax schedule is quadratic.

From these four examples, one notices that taxes on workers are equivalent to taxes on firms only if the tax schedules are affine. This can readily be checked by inspection of the definition of $B_{j}$ (equation (15)): when $\beta_{j}$ corresponds to $\alpha_{0}$, (that is, when they are both lump sum or both the coefficient of the linear term or 
the coefficient of the quadratic term, ...) the term $\bar{W}_{w \beta_{j}} / \bar{W}_{\beta_{j}}-\underline{W}_{w \alpha_{0}} / \underline{W}_{\alpha_{0}}$ vanishes. There remains only the term $\underline{W}_{w w} / \underline{W}_{w}-\bar{W}_{w w} / \bar{W}_{w}$ in the curly brackets. This term vanishes when the taxation schedule is affine. It is generally different from zero in the other cases. This yields the following Corollary:

Corollary 2 Taxes on workers are equivalent to taxes on firms only if the tax schedules are affine.

Note that the tax schedule is often piecewise linear, that is, linear over intervals but non linear as a whole. Extending the above argument suggests that a transfer of taxes from firms to workers is irrelevant to employment if the market wage remains in the same initial interval (that is, for relatively minor tax reforms). On the other hand, for major tax reforms, the market wage will move to another interval. The argument that a switch of taxes from firms to workers is relevant to employment for non linear tax schedules will then apply.

\subsection{Marginal Taxes and Progressivity}

In this section we study how the tax parameters should move to implement a budget-neutral tax reform that would improve employment. We then make the link with the literature on tax progressivity and imperfect labor markets ${ }^{8}$ (see Hersoug (1984), Hoel (1990), Lockwood and Manning (1993), Koskela and Vilmunen (1996), Pissarides (1998) or Sørensen (1999)).

Let us first assume that only workers are taxed $\left(\bar{W}_{w}=1\right)$. This assumption allows to isolate the impact of marginal taxes on employment from the effect of tax incidence that has been explained in the previouss section. Let us then focus on the class polynomial tax schedules and let us assume that lump sum transfers

\footnotetext{
${ }^{8}$ In this model, we have assumed that the number of worked hours is exogenous. Using simulations, Sørensen (1999) shows that results remain qualitatively unchanged when the number of worked hours is endogenous.
} 
$\alpha_{0}$ are available instruments:

$$
\underline{w}=\alpha_{0}+\sum_{i \neq 0}^{n-1} \alpha_{i} w^{i}
$$

This implies that $\underline{W}_{\alpha_{0}}=1, \underline{W}_{\alpha_{i}}=w^{i}, \underline{W}_{w \alpha_{0}}=0$ and $\underline{W}_{w \alpha_{i}}=i w^{i-1}$. Thus, by (14), improvements in employment are always possible:

$$
d L=\sum_{i \neq 0}^{n-1} A_{i \neq 0} d \alpha_{i}=\Omega \sum_{i \neq 0}^{n-1} i w^{i-1} d \alpha_{i} .
$$

This expression always has the same sign. Hence, an increase in any parameter $\alpha_{i \neq 0}$ moves employment in the same direction. In order to sign $\Omega$ (see (16)), we make the same assumption as Rasmussen (1993, 1997, 1998), Koskela and Vilmunen (1996) or Koskela and Schöb (1999) about the lump sum instrument $\alpha_{o}$

Dupuit-Laffer Assumption All parameters $\alpha_{i \neq 0}$ being constant, $\alpha_{o}$ lies on the increasing part of the Dupuit-Laffer curve. That is an increase in $\alpha_{o}$ reduces the government budget $G$.

This assumption may be expressed as

$$
\left[\frac{d G}{d \alpha_{0}}\right]_{\alpha_{i \neq 0}=\text { Constan } t}=G_{\alpha_{0}}+G_{w}\left[\frac{d w}{d \alpha_{0}}\right]_{F=0}=G_{\alpha_{0}}-G_{w} \frac{F_{\alpha_{0}}}{F_{w}}<0 .
$$

The Dupuit-Laffer assumption states that the direct effect of $\alpha_{0}$ on the government spending is stronger than the (indirect) effect through the wage setting. This is a reasonable assumption for rational governments. The denominator of $\Omega$ is $\left[\frac{G_{w}}{G_{\alpha_{0}}}-\frac{F_{w}}{F_{\alpha_{0}}}\right] F_{\alpha_{0}}=\frac{G_{w}}{G_{\alpha_{0}}} F_{\alpha_{0}}-F_{w}=-\frac{F_{w}}{G_{\alpha_{0}}}\left[G_{\alpha_{0}}-G_{w} \frac{F_{\alpha_{0}}}{F_{w}}\right]$. Using the above assumption, the fact that from the second order condition, $F_{w}<0$ and the result that $G_{\alpha_{0}}<0$ ( $\alpha_{o}$ is a lump sum given to workers that, ceteris paribus, decreases the government budget) implies that $\Omega$ has the same sign as $\left(L^{D^{\prime}} Q\right)$. As we have assumed that $L^{D^{\prime}}<0$, any decrease in the tax parameters $\alpha_{i \neq 0}$ improves employment and keeps the budget unchanged iff $Q>0$. In the generic model the term $Q$ is positive. 
Proposition 3 Suppose that a polynomial tax schedule is used and that the Dupuit-Laffer assumption holds. Then, any decrease in the tax parameters $\alpha_{i \neq 0}$ improves employment and keeps the budget unchanged in the generic model, i.e. in the union bargaining model, the search model or the efficiency wage model.

If the tax scheme is linear so that $\underline{w}=\alpha_{0}+\alpha_{1} w$, then the Corollary implies that $\alpha_{1}$ must be reduced to increase employment, that is, the marginal tax rate must increase. This corresponds to the Lockwood and Manning's (1993) results for which increases in marginal tax to workers reduce wage pressure and enhance employment in union models. This result holds for non linear tax schedules. Our proposition and corollary extend that result to a broader class of models.

We now establish the link with tax progressivity. For simplicity we focus on linear tax schedules. Tax progression can be defined as residual progression (see Musgrave and Thin (1948), Lambert (1993) or Koskela and Vilmunen (1996)):

$$
\operatorname{Prog}=\frac{\underline{w} / w}{d \underline{w} / d w} .
$$

or

$$
\operatorname{Prog}=1+\frac{\alpha_{0}}{\alpha_{1} w}
$$

Therefore,

$$
d \operatorname{Prog}=\frac{1}{\alpha_{1} w}\left[\frac{d \alpha_{0}}{d \alpha_{1}}-\frac{\alpha_{0}}{\alpha_{1}}-\frac{\alpha_{0}}{w} \frac{d w}{d \alpha_{1}}\right] d \alpha_{1} .
$$

For the sake of realism, it is reasonable to assume positive lump sum transfers $\alpha_{0} \geq 0$. Indeed, most tax schedules are progressive and provide positive exemptions which can be equated to such transfers $\alpha_{0}$. From (4) and (17),

$$
d L=\Omega d \alpha_{1}=L^{D^{\prime}} d w .
$$

Thus, $d w / d \alpha_{1}=\Omega / L^{D^{\prime}}$ which is positive in the union bargaining model, in the search model and in the efficiency wage model. Also, introducing (19) in equation 
(23) of Appendix 1, and rearranging terms yields

$$
\frac{d \alpha_{0}}{d \alpha_{1}}=-\frac{G_{\alpha_{1}}-G_{w} \frac{F_{\alpha_{1}}}{F_{w}}}{G_{\alpha_{0}}-G_{w} \frac{F_{\alpha_{0}}}{F_{w}}} .
$$

Using the Dupuit-Laffer argument for both tax parameters $\alpha_{0}$ and $\alpha_{1}$, we can check that this expression is negative. When $\alpha_{0} \geq 0$, it is easy to show that $d$ Prog $/ d \alpha_{1}<0$. By Proposition 3, we have the following corollary:

Corollary 3 Suppose that a progressive linear tax schedule $\left(\alpha_{0} \geq 0\right)$ is used and that the Dupuit-Laffer assumption holds for $\alpha_{0}$ and $\alpha_{1}$. Then, an increase in tax progressivity increases employment and keeps the budget unchanged in the generic model, i.e. in the union bargaining models, the search models and the efficiency wage models.

\section{Concluding Remarks}

In this paper, we have gathered the main features of models such as union-firm wage bargaining, search and efficiency wage in a generic model. This allows us to derive general conclusions on the equivalence of taxes paid by workers and by employers, and on the effects of tax progressivity. Results indicate that when the taxation scheme is non linear, taxing workers is not equivalent to taxing firms. Moreover, increasing progressivity is good for employment since it reduces the incentives to increase wages.

\section{Appendix 1: Proof of Proposition 1}

Totally differentiating constraints (1) and (2) yields the following system:

$$
\begin{aligned}
F_{w}(w, \alpha, \beta) d w+\sum_{i} F_{\alpha_{i}}(w, \alpha, \beta) d \alpha_{i}+\sum_{j} F_{\beta_{j}}(w, \alpha, \beta) d \beta_{j} & =0 \\
G_{w}(w, \alpha, \beta) d w+\sum_{i} G_{\alpha_{i}}(w, \alpha, \beta) d \alpha_{i}+\sum_{j} G_{\beta_{j}}(w, \alpha, \beta) d \beta_{j} & =0 .
\end{aligned}
$$


We suppose that there exists at least one taxation parameter $\alpha_{0}$ (or $\beta_{0}$ ) under the government's control that has an impact on the wage and the budget: $F_{\alpha_{0}}$, $G_{\alpha_{0}} \neq 0$. We solve the two equations to find $d \alpha_{0}$ and $d w$. Rearranging terms in (20) and (21) gives

$$
\begin{aligned}
d \alpha_{0} & =\left(1 / F_{\alpha_{0}}\right)\left(-F_{w} d w-\sum_{i \neq 0} F_{\alpha_{i}} d \alpha_{i}-\sum_{j} F_{\beta_{j}} d \beta_{j}\right), \\
d \alpha_{0} & =\left(1 / G_{\alpha_{0}}\right)\left(-G_{w} d w-\sum_{i \neq 0} G_{\alpha_{i}} d \alpha_{i}-\sum_{j} G_{\beta_{j}} d \beta_{j}\right) .
\end{aligned}
$$

Therefore, we have

$$
\left[G_{w}-\frac{G_{\alpha_{0}}}{F_{\alpha_{0}}} F_{w}\right] d w=-\sum_{i \neq 0}\left[G_{\alpha_{i}}-\frac{G_{\alpha_{0}}}{F_{\alpha_{0}}} F_{\alpha_{i}}\right] d \alpha_{i}-\sum_{j}\left[G_{\beta_{j}}-\frac{G_{\alpha_{0}}}{F_{\alpha_{0}}} F_{\beta_{j}}\right] d \beta_{j} .
$$

For each change in the $\alpha_{i}(i \neq 0)$ or $\beta_{j}$, the market wage must change according to (24) and $\alpha_{0}$ must be adjusted according to (22) or (23) in order to fulfill both wage and budget equations. This yields expressions (5), (6) and (7) in the text.

\section{Appendix 2: Proof of Proposition 2}

Part (i) We have

$$
F_{\alpha_{i}}=\underline{W}_{\alpha_{i}}\left[\underline{W}_{w} Q_{1}+\bar{W}_{w} R_{1}\right]+\underline{W}_{w \alpha_{i}} Q(\underline{w}, \bar{w})
$$

Moreover, $G_{\alpha_{i}}=\Psi_{1} \underline{W}_{\alpha_{i}}$ and $G_{\alpha_{i}} / G_{\alpha 0}=\underline{W}_{\alpha_{i}} / \underline{W}_{\alpha 0}$ in equation (6). Using equation (25), we can simplify (6) to:

$$
A_{i \neq 0}=-L^{D^{\prime}} \frac{Q(\underline{w}, \bar{w})}{\left[\frac{G_{w}}{G_{\alpha_{0}}}-\frac{F_{w}}{F_{\alpha_{0}}}\right] F_{\alpha_{0}}} \bar{W}_{w} \underline{W}_{\alpha_{i}}\left[\frac{\underline{W}_{w \alpha_{0}}}{\underline{W_{\alpha_{0}}}}-\frac{\underline{W}_{w \alpha_{i}}}{\underline{W_{\alpha_{i}}}}\right] .
$$

Part (ii) We have

$$
\frac{G_{\beta_{j}}}{G_{\alpha_{0}}}-\frac{\bar{W}_{\beta_{j}}}{\bar{W}_{w}} \frac{G_{w}}{G_{\alpha_{0}}}=\frac{1}{G_{\alpha_{0}}}\left[\Psi_{2} \bar{W}_{\beta_{j}}-\frac{\bar{W}_{\beta_{j}}}{\bar{W}_{w}}\left(\Psi_{1} \underline{W}_{w}+\Psi_{2} \bar{W}_{w}\right)\right]=-\frac{\bar{W}_{\beta_{j}}}{\bar{W}_{w}} \frac{\underline{W}_{w}}{\underline{W}_{\alpha_{0}}},
$$


and

$$
\begin{aligned}
F_{\alpha_{0}} & =\underline{W}_{\alpha_{0}}\left[\underline{W}_{w} Q_{1}+\bar{W}_{w} R_{1}\right]+\underline{W}_{w \alpha_{0}} Q(\underline{w}, \bar{w}), \\
F_{\beta_{j}} & =\underline{W}_{w} Q_{2} \bar{W}_{\beta_{j}}+\bar{W}_{w \beta_{j}} R+\bar{W}_{w} R_{2} \bar{W}_{\beta_{j}}, \\
F_{w} & =\underline{W}_{w w} Q+\bar{W}_{w w} R+\underline{W}_{w}\left(Q_{1} \underline{W}_{w}+Q_{2} \bar{W}_{w}\right)+\bar{W}_{w}\left(R_{1} \underline{W}_{w}+R_{2} \bar{W}_{w}\right) .
\end{aligned}
$$

After some algebraic manipulations, we get

$$
\frac{F_{\beta_{j}}}{F_{\alpha_{0}}}-\frac{\bar{W}_{\beta_{j}}}{\bar{W}_{w}} \frac{F_{w}}{F_{\alpha_{0}}}=-\frac{\bar{W}_{\beta_{j}}}{\bar{W}_{w}} \frac{\underline{W}_{w}}{\underline{W}_{\alpha_{0}}}-\frac{X_{j} \bar{W}_{\beta_{j}}}{\bar{W}_{w} F_{\alpha_{0}}} .
$$

with

$$
X_{j} \equiv Q(\underline{w}, \bar{w})\left[\underline{W}_{w w}-\frac{\underline{W}_{w}}{\underline{W}_{\alpha_{0}}} \underline{W}_{w \alpha_{0}}\right]+R(\underline{w}, \bar{w})\left[\bar{W}_{w w}-{\overline{W_{w}}}_{\bar{W}_{\beta_{j}}} \bar{W}_{w \beta_{j}}\right] .
$$

Hence,

$$
B_{j}=-L^{D^{\prime}} \frac{X_{j} \bar{W}_{\beta_{j}}}{\left[\frac{G_{w}}{G_{\alpha_{0}}}-\frac{F_{w}}{F_{\alpha_{0}}}\right] F_{\alpha_{0}}} .
$$

Since $Q$ and $R \neq 0$, this last expression implies by (10)

$$
B_{j}=-\frac{Q(\underline{w}, \bar{w})}{\left[\frac{G_{w}}{G_{\alpha_{0}}}-\frac{F_{w}}{F_{\alpha_{0}}}\right] F_{\alpha_{0}}} \underline{W}_{w} \bar{W}_{\beta_{j}}\left\{\left[\frac{\underline{W_{w w}}}{\underline{W}_{w}}-\frac{\bar{W}_{w w}}{\bar{W}_{w}}\right]+\left[\frac{\bar{W}_{w \beta_{j}}}{\bar{W}_{\beta_{j}}}-\frac{\underline{W}_{w \alpha_{0}}}{\underline{W}_{\alpha_{0}}}\right]\right\}
$$

Since $F_{\alpha_{0}}, \underline{W}_{\alpha_{i}}, Q(\underline{w}, \bar{w}), \frac{G_{w}}{G_{\alpha_{0}}}-\frac{F_{w}}{F_{\alpha_{0}}}$ and $\bar{W}_{w}$ are different from zero, we have the proposition.

\section{References}

Akerlof G. A. and Yellen J.L. (1990), The Fair Wage-Effort Hypothesis and Unemployment, Quarterly Journal of Economics 105, 255-283.

Andersen T.M. and Rasmussen B.S. (1999), Effort, Taxation and Unemployment, Economics Letters 62, 97-103. 
Blinder A. (1988), The Challenge of High Unemployment, American Economic Review 78, 1-15.

Booth A. (1995), The Economics of the Trade Union, Cambridge University Press: Cambridge.

Calmfors L. (1990), Wage Formation and Macroeconomic Policy in the Nordic Countries: A Summary, pp. 11-60 in Calmfors L. (ed.), Wage Formation and Macroeconomic Policy in the Nordic Countries, SNS, Stockholm.

Dalton H. (1954), Principles of Public Finance, Routledge and Kegan, London. European Commission (1994), Growth, Competitiveness, Employment: the Challenges and Ways Forward into the 21st Century, White Paper, Office for Official Publications of the European Community, Luxembourg.

Goerke L. (1999), The Wedge, Manchester School, forthcoming. Hersoug T. (1984), Union Response to Tax Changes, Oxford Economic Papers $36,37-51$.

Hoel M. (1990), Efficiency Wages and Income Taxes, Journal of Economics 51, 89-99.

Koskela E. and Vilmunen J. (1996), Tax Progression Is Good for Employment in Popular Models of Trade Union Behaviour, Labour Economics 3, 65-80.

Koskela E. and Schöb R. (1999), Does the Composition of Wage and Payroll Taxes Matter under Nash Bargaining?, Economics Letters 64, 343-349.

Lambert P.J. (1993), The Distribution and Redistribution of Income - A Mathematical Analysis, Manchester University Press: Manchester.

Layard R., Nickell S. and Jackman R. (1991), Unemployment - Macroeconomic Performance and the Labour Market, Oxford University Press, Oxford.

Lockwood B. and Manning A. (1993), Wage Setting and the Tax System: Theory and Evidence for the United Kingdom, Journal of Public Economics 52, 1-29. 
Musgrave R.A. and Thin T. (1948), Income Tax Progression, 1929-1948, Journal of Political Economy 56, 498-514.

Picard P.M. and Toulemonde E. (1998), On the Equivalence of Taxes Paid by Employers and Employees, Working Paper 1999-18, University of Aarhus.

Pisauro G. (1991), The Effect of Taxes on Labour in Efficiency Wage Models, Journal of Public Economics 46, 329-345.

Pissarides C.A. (1990), Equilibrium Unemployment Theory, Basil Blackwell: Oxford.

Pissarides C.A. (1998), The Impact of Employment Tax Cuts on Unemployment and Wages; The Role of Unemployment Benefits and Tax Structure, European Economic Review 42, 155-183.

Rasmussen B.S. (1993), Wage Formation and the Structure of Labour Taxation - Income vs. Payroll Taxes, mimeo, Department of Economics, University of Aarhus.

Rasmussen B.S. (1997), Non-Equivalence of Employment and Payroll Taxes in Imperfectly Competitive Labour Markets, Working Paper No 1997-22, Department of Economics, University of Aarhus.

Rasmussen B.S. (1998), Long Run Effects of Employment and Payroll Taxes in an Efficiency Wage Model, Economics Letters 58, 245-253.

Shapiro C. and Stiglitz J. (1984), Equilibrium Unemployment as a Worker Discipline Device, American Economic Review, 74, 433-444.

Solow, R.M. (1979), Another Possible Source of Wage Stickiness, Journal of Macroeconomics, 1, 79-82.

Sørensen, P.B. (1999), Optimal Tax Progressivity in Imperfect Labour Markets, Labour Economics, 6, 435-452. 
Tyrväinen T. (1995) "Real Wage Resistance and Unemployment: Multivariate Analysis of Cointegrating Relations in 10 OECD Countries", The OECD Jobs Study Working Papers No.10. 